Ming Bai ORCID iD: 0000-0003-4172-1747

\title{
MiR-625-5p/PKM2 negatively regulates melanoma glycolysis state
}

\author{
Hailin Zhang, Cheng Feng, Mingzi Zhang, Zeng Ang, Loubin Si, Nanze Yu, Ming Bai* \\ Department of Plastic Surgery, Peking Union Medical College Hospital, Beijing, China
}

Corresponding author: Ming Bai, 1 Shuaifuyuan, Dongcheng District, Peking Union Medical College Hospital (East), 100730, Beijing, China. Email: sunshine_xzs@yeah.net

\begin{abstract}
PKM2 plays an important role in cancer glycolysis, however, the link of PKM2 and microRNAs (miRNAs) in melanoma is still unclear. The study will investigate the role of miRNAs in regulating PKM2 mediated melanoma cell glycolysis. We found that high PKM2 expression in melanoma tissues and cell lines was positively associated with glycolysis. Further study indicated that miR-625-5p regulated PKM2 expression on mRNA and protein levels in melanoma cells. There was negative relationship between miR-625-5p and PKM2 expression in the clinical melanoma samples. These findings provide an evidence that miR-625-5p/PKM2 plays a role in melanoma cell glucose metabolism.
\end{abstract}

This is the author manuscript accepted for publication and undergone full peer review but has not been through the copyediting, typesetting, pagination and proofreading process, which may lead to differences between this version and the Version of Record. Please cite this article as doi: 10.1002/jcb.26917.

This article is protected by copyright. All rights reserved. 


\section{Graphical Abstract}

PKM2 promoted melanoma cell glycolysis and drug resistance and demonstrated that miR-625-5p regulated PKM2 expression in melanoma cells. MiR-625-5p is one of miRNAs involved in cancer cell glucose metabolism targeting PKM2, however, our data hopefully improve current understanding of the regulatory network of cancer metabolism and provide potential targets for the development of cancer therapeutic methods.
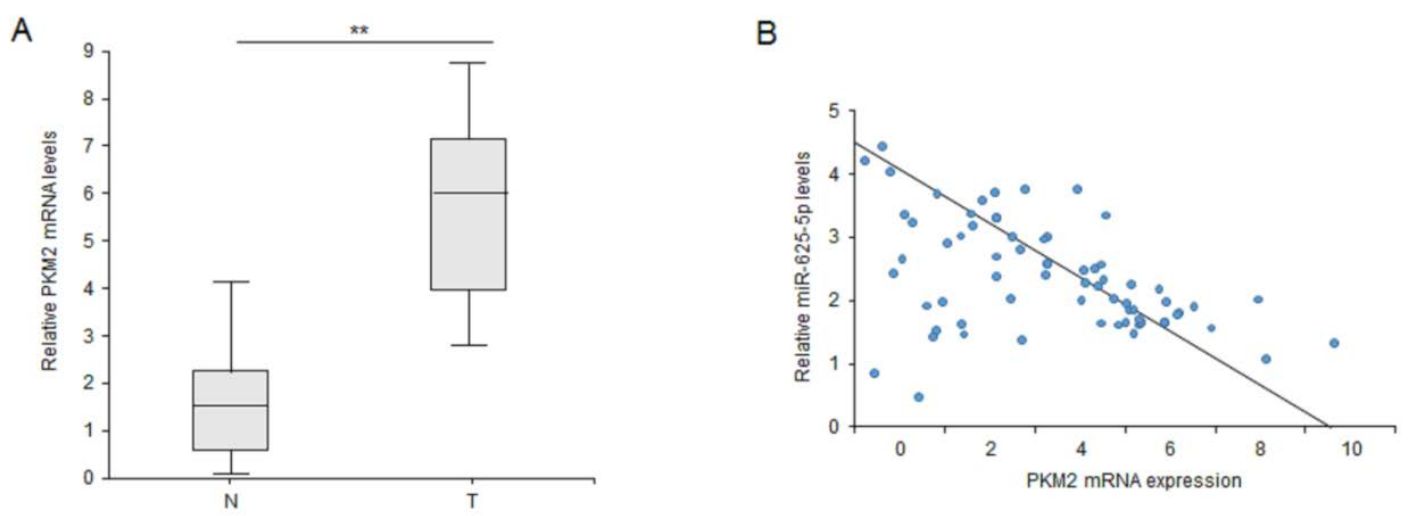

Key words: miR-625-5p, melanoma, glycolysis, PKM2

\section{Background}

Melanoma is the most aggressive type of skin cancer. There are many new cases of melanoma every year and the prognosis of melanoma is very bad with low survival rates of patients [1]. There are great achievements in melanoma therapy and diagnosis, however, the therapy for melanoma is still not good. Aerobic glycolysis is a hallmark of cancer including melanoma [2-4]. Although the mechanism of glycolysis is well studied, the mechanisms of glycolysis are not fully understood.

PKM2 plays an important role in cancer [5-6]. The cellular functions of PKM2 in cancer include: accelerating cell proliferation, migration, invasion, autophagy, aerobic glycolysis, and other biological progresses of cancer development. PKM2 is closely correlated with

This article is protected by copyright. All rights reserved. 
glycolysis in various cancer types such as colorectal cancer [10], ovarian cancer [13] and others. PKM2 expression is regulated by signal pathways, microRNAs (miRNAs), tumor hypoxia, microenvironment [17-21]. It is reported that PKM2 is involved in melanoma glycolysis [22-23].

More and more studies indicate the important roles of miRNAs in gene regulation. To explore the mechanism of the role of PKM2 mediated glycolysis and drug resistance in melanoma regulated by miRNAs. The prediction was done by Targetscan and miR-6255p was verified as a potential miRNA that regulated PKM2 expression. The previous studies show that miR-625 is a tumor suppressor that inhibits the development and progression of melanoma and is potentially a new diagnostic marker and therapeutic target of malignant melanoma [24-25]. For example: Fang et al. reported that miR-625 expression was frequently decreased in malignant melanoma and ectopic expression of miR-625 suppressed proliferation, wound healing, migration, and tumorgenicity in malignant melanoma by targeting SOX2 partially [24]. Kang et al. demonstrated that miR-625 were significantly decreased in cutaneous melanoma tissues and its expression level was significantly associated with tumor thickness and stage. The overall survival rate was significantly lower in the patients with low miR-625 level than in those with high level [25].

In this study, we will investigate the role of miR-625-5p in melanoma by targeting PKM2. The results showed that lack of miR-625-5p expression in melanoma cells suppressed cell proliferation, glycolysis and reversed the drug resistance by suppressing PKM2 expression. Therefore, targeting PKM2 or up-regulating miR-625-5p could be valuable to overcome drug resistance and glycolysis of melanoma.

This article is protected by copyright. All rights reserved. 


\section{Methods}

\section{Cell lines and cell culture}

Human melanoma cells (A2085, A375, A875, Mel-RM, M14, M21 and WM35) were stored in our lab. The cells were cultured in Dulbecco's modified eagle medium (DMEM, Invitrogen, USA) with 10\% fetal bovine serum (FBS), streptomycin (100U/mL) and penicillin (100 U/mL). Normal skin cells HFE was cultured in DMEM with 10\% FBS, EGF (100ng/ml). Cells were cultured under a condition of a humidified atmosphere of 5\% carbon dioxide at $37^{\circ} \mathrm{C}$.

\section{RT-PCR}

Total RNA was extracted from the melanoma cells using Trizol (Invitrogen, CA, USA) referring to the protocol. For mRNA expression analysis, real time RT-PCR was performed using a sequence detector (ABI-Prism, Applied Biosystems) following the instructions. The relative expression levels were calculated by the $2^{-\Delta \Delta \mathrm{Ct}}$ method. All data were normalized to $\beta$-actin for mRNA. For miRNA expression analysis, the steps were the same to mRNA analysis. U6 for miRNA. The primers are as the following:
Name
Forward primer $\left(5^{\prime}-3^{\prime}\right)$
Reverse primer $\left(5^{\prime}-3^{\prime}\right)$
MiR-625-5p
CCAGGGGGAAAGTTCTATAGTCC
CAGTGCGTGTCGTGGAGT
$\beta$-actin
GTGGCCGAGGACTTTGATTG
CTGTAACAACGCATCTCATATT
U6
GCGCGTCGTGAAGCGTTC
GTGCAGGGTCCGAGGT

This article is protected by copyright. All rights reserved. 


\section{Cell proliferation}

A2085 and M14 cells were transfected with PKM2 siRNAs (100nM), PKM2 lentiviral particles or miR-625-5p mimics (50nM) for 24h in 6-well plates and then seeded into 96well plates for $0,1,2,3,4$ and 5 days. The cell viability was determined using the Cell Counting Kit-8 (CCK-8) according to the manufacturer's protocols.

\section{Western blot analysis}

Total protein was isolated from cells using RIPA buffer $(50 \mathrm{mM}$ Tris- $\mathrm{HCl}, \mathrm{pH} 8.0$, 150mM NaCl, 5mM EDTA, 0.1\% SDS and 1\% NP-40) supplemented with cocktail. Protein concentration was measured using the Bradford assay kit. Equal amount of proteins were loaded and separated by SDS-polyacrylamide gel electrophoresis. Antibodies for PKM2 (Cell signaling) and mTOR were used for blotting. $\beta$-Actin (Abmart; 1:5,000) served as loading control.

\section{Lactate production, ATP uptake and glucose consumption}

The supernatants from the melanoma cells with miR-625-5p mimics (50nM), PKM2 lentiviral particles or PKM2 siRNA (100nM) transfection were used for the assay for lactate production, ATP uptake and glucose consumption. Glucose consumption and lactate production were quantified according to the protocols of (Invitrogen).

This article is protected by copyright. All rights reserved. 


\section{Patients and tissue specimens}

Primary melanoma samples were obtained from patients undergoing tumor resection. Informed consent was obtained from Peking Union Medical College Hospital (Beijing, China).

\section{Statistical analysis}

All experiments were performed in triplicate and the data are expressed as mean \pm standard deviation (SD). The significance of the differences between two groups of data was evaluated using a two-tailed Student's t-test or Mann-Whitney U-test. All statistical analyses were carried out using SPSS software version 19.0 for Windows (SPSS Inc., IL, USA). A $P$-value $<0.05$ was considered statistically significant.

\section{Results}

\section{PKM2 expression is up-regulated in melanoma samples}

To know the role of PKM2 in melanoma, PKM2 expression was detected in melanoma tissues and normal tissues and the results indicated PKM2 mRNA increased significantly in melanoma tissues (Figure 1A). PKM2 protein levels were also higher in melanoma tissues than the adjacent normal tissues (Figure 1B). The data was verified in melanoma cell lines, which showed that PKM2 mRNA and protein levels increased in the cells, specially, in M14 and A2085 cells (Figure 1C-D). These data suggested that PKM2 may function as an oncogene in melanoma.

\section{Down-regulation of PKM2 suppresses glycolysis and reverses the drug resistance}

To investigate the impact of PKM2 on glycolysis and drug resistance, M14 and A2085 were treated with BRAF inhibitors and constructed the resistant cells M14-R and A2085R. M14, M14R and A2085, A2085R were treated with BRAF inhibitors, and then cell 
proliferation was analyzed to confirm that M14-R and A2085-R cells were resistant to BRAF inhibitors (Figure 2A-B). The above cells were transfected with PKM2 siRNAs and then cell proliferation was assayed, and we found that knocking down PKM2 expression in the melanoma cells showed more sensitive to BRAF inhibitors (Figure 2CD). Lactic acid production was measured in M14, M14R and A2085, A2085 cells, and it was found that the resistant cells showed more lactate production compared to the parent cells; in the cells with PKM2 down-regulation, the lactate production was suppressed (Figure 2E-F). ATP production was measured in M14, M14R and A2085, A2085 cells, and it was found that the resistant cells showed more ATP production compared to the parent cells; in the cells with PKM2 down-regulation, the ATP production was suppressed (Figure 2G-H). Glucose consumption was measured in M14, M14R and A2085, A2085 cells, and it was found that the resistant cells showed more glucose consumption compared to the parent cells; in the cells with PKM2 down-regulation, the glucose consumption was suppressed (Figure 2I-J).

\section{PKM2 is a target gene of miR-625-5p in melanoma cells}

It was predicted that PKM2 was a target gene of miR-625-5p (Figure 3A). Firstly, the luciferase assay was used to confirm that PKM2 was the target gene of miR-625-5p. It was shown that luciferase activity in cells was down-regulated significantly when the cells were co-transfected with miR-625-5p mimics and wide type of PKM2 3'UTR (Figure 3B and 3C). To know the PKM2 expression on mRNA and protein levels, melanoma cells were transfected with miR-625-5p mimics and PKM2 expression mRNA decreased in cells (Figure 3D and 3E). The result was confirmed by western blotting (Figure 3F).

This article is protected by copyright. All rights reserved. 


\section{MiR-625-5p suppresses cell proliferation and glycolysis}

To know the impact of miR-625-5p on glycolysis and drug resistance, M14, M14R and A2085, A2085R cells were transfected with miR-625-5p or PKM2 and then drug responses was assayed. Melanoma cell proliferation was assayed, and we found that miR625-5p made the cells become more sensitive to BRAF inhibitor in M14R and A2085R cells driven by PKM2 expression (Figure 4A-B). Lactic acid production was measured in M14 and A2085 cells with miR-625-5p overexpression, and miR-625-5p suppressed lactate production in the cells with PKM2 overexpression (Figure 4C-D). ATP production was measured in M14 and A2085 cells with miR-625-5p overexpression, and miR-6255p suppressed ATP production in the cells with PKM2 overexpression (Figure 4E-F). Glucose consumption was measured in M14, A2085 and their resistant cells with miR625-5p overexpression, and miR-625-5p suppressed ATP production in the cells with PKM2 overexpression or drug resistant cells (Figure 4G-H).

\section{MiR-625-5p expression is down-regulated and methylated in melanoma}

To know the role of miR-625-5p in melanoma, miR-625-5p expression was detected in melanoma tissues and normal tissues. The results indicated miR-625-5p decreased significantly in melanoma tissues (Figure 5A). The data was verified in melanoma cell lines, which showed that miR-625-5p levels decreased in the cells, specially, in M14 and A2085 cells (Figure 5B). As a potential tumor suppressor, whether miR-625-5p is methylated? We determined if miR-625-5p expression was silenced by examining the reactivation of miR-625-5p expression in melanoma cells following treatment with the demethylating agent 5-aza-2'-deoxycytidine (5-AZA). MiR-625-5p expression levels recovered by $3-5$ folds after 5-AZA treatment (Figure 5C). Furthermore, we detected

This article is protected by copyright. All rights reserved. 
CpG island methylation of miR-625-5p in melanoma cell lines by BSP analysis of multiple clones in the cell lines. Bisulfite sequencing in all the above melanoma cell lines confirmed marked methylation of the promoter region of miR-625-5p (Figure 5D).

\section{MiR-625-5p expression is negatively related to PKM2 expression in melanoma tissues}

PKM2 mRNA levels were higher in melanoma tissues than the normal controls (Figure 6A). The analysis between miR-625-5p and PKM2 showed that miR-625-5p was negatively correlated with PKM2 mRNA levels in melanoma samples (Figure 6B). Furthermore, we analyzed the relationship between of miR-625-5p expression and the clinical features. It showed that miR-625-5p was related to TNM stage, tumor size and poor differentiation (Table 1). We also analyzed the relationship between of PKM2 expression and the clinical features. It showed that PKM2 was related to TNM stage, tumor size and poor differentiation (Table 2).

\section{Discussion}

MiRNAs is a class of non-coding RNAs with about 20-20 nucleotides and contribute to cancer development and progression by regulating the progress of cancer [1-4]. MiRNAs are involved in many physiological or pathological progresses such as cell proliferation, apoptosis, differentiation, energy metabolism, metastasis and immune responses [5]. MiRNAs are frequently dysregulated in human melanoma that they can function as tumor inhibitors or promoters [2]. Although there are many reports about important roles on miRNA in tumor progression, the glycolysis in melanoma regulated by miRNAs merits investigation . The reported miRNAs involved in glycolysis in melanoma includes let-7a

This article is protected by copyright. All rights reserved. 
[26], miR-18b [27], miR-138 [28] and miR-370 [29]. But, the regulation of miRNAs in melanoma glycolysis still needs to be investigated. In the study, we confirmed that PKM2 promoted cell proliferation and glycolysis in melanoma cells, which was regulated by miR-625-5p.

Pyruvate kinase (PK) is the enzyme responsible for catalyzing the last step of glycolysis. Of the four PK isoforms expressed in mammalian cells, PKM2 has generated the most interest due to its impact on changes in cellular metabolism observed in cancer as well as in activated immune cells [17-18]. The enzymatic activity of PKM2 is heavily regulated by endogenous allosteric effectors as well as by intracellular signaling pathways, affecting both the enzymatic activity of PKM2 as a PK and the regulation of the recently described non-canonical nuclear functions of PKM2 [17-18]. Accumulating evidence from experimental and clinical studies indicate that PKM2 is a critical molecule in cancer progression such as metabolism and growth of cancer [19-20]. Our study showed that PKM2 expression in melanoma tissues and cell lines were higher than its expression in normal melanoma tissues or cell line. The results of cellular functions showed that PKM2 promoted melanoma cell growth and glycolysis including lactate production, ATP production and glucose consumption. The results were consistent with the previous studies from other cancers.

MiR-625-5p is confirmed as a miRNA that regulating PKM2 expression in melanoma cells. The luciferase assay was used to verify that PKM2 is a target gene of miR-625-5p. High expression of miR-625-5p negatively correlates with clinical prognosis of melanoma by targeting PKM2. In our study, we identified that miR-625-5p was downregulated in melanoma tissues. The cellular function analysis showed that miR-625-5p

This article is protected by copyright. All rights reserved. 
suppressed melanoma cell proliferation. MiR-625-5p could suppress lactate production, ATP production and glucose consumption in melanoma cells. PKM2 is a target gene of miR-625-5p, which indicates miR-625-5p is a tumor suppressor miRNA in melanoma cells.

In summary, our study for the first time demonstrated that PKM2 promoted melanoma cell glycolysis and cell proliferation and demonstrated that miR-625-5p regulated PKM2 expression in melanoma cells. MiR-625-5p is one of miRNAs involved in cancer cell glucose metabolism targeting PKM2, however, our data will hopefully improve current understanding of the regulatory network of cancer metabolism and provide potential targets for the development of cancer therapeutic methods.

\section{Conflict of interests}

None.

\section{References}

1. Fattore L, Costantini S, Malpicci D, Ruggiero CF, Ascierto PA, Croce CM, Mancini R, Ciliberto G. MicroRNAs in melanoma development and resistance to target therapy. Oncotarget. 2017;8:22262-22278.

2. Ling H, Girnita L, Buda O, Calin GA. Non-coding RNAs: the cancer genome dark matter that matters! Clin Chem Lab Med. 2017;55:705-714.

3. Varamo C, Occelli M, Vivenza D, Merlano M, Lo Nigro C. MicroRNAs role as potential biomarkers and key regulators in melanoma. Genes Chromosomes Cancer. 2017;56:3-10.

This article is protected by copyright. All rights reserved. 
4. Mannavola F, Tucci M, Felici C, Stucci S, Silvestris F. miRNAs in melanoma: a defined role in tumor progression and metastasis. Expert Rev Clin Immunol. 2016;12:79-89.

5. Dayton TL, Jacks T, Vander Heiden MG. PKM2, cancer metabolism, and the road ahead. EMBO Rep. 2016;17:1721-1730.

6. Dong G, Mao Q, Xia W, Xu Y, Wang J, Xu L, Jiang F. PKM2 and cancer: The function of PKM2 beyond glycolysis. Oncol Lett. 2016;11:1980-1986.

7. $\quad$ Li N, Feng L, Liu H, Wang J, Kasembeli M, Tran MK, Tweardy DJ, Lin SH, Chen J. PARP Inhibition Suppresses Growth of EGFR-Mutant Cancers by Targeting Nuclear PKM2. Cell Rep. 2016. pii: S2211-1247(16)30359-X.

8. Hsu MC, Hung WC, Yamaguchi H, Lim SO, Liao HW, Tsai CH, Hung MC. Extracellular PKM2 induces cancer proliferation by activating the EGFR signaling pathway. Am J Cancer Res. 2016;6:628-638.

9. Wang C, Jiang J, Ji J, Cai Q, Chen X, Yu Y, Zhu Z, Zhang J. PKM2 promotes cell migration and inhibits autophagy by mediating PI3K/AKT activation and contributes to the malignant development of gastric cancer. Sci Rep. 2017;7:2886.

10. Yan XL, Zhang XB, Ao R, Guan L. Effects of shRNA-mediated silencing of PKM2 gene on aerobic glycolysis, cell migration, cell invasion and apoptosis in colorectal cancer cells. J Cell Biochem. 2017.

11. Guo M, Zhao X, Yuan X, Jiang J, Li P. MiR-let-7a inhibits cell proliferation, migration, and invasion by down-regulating PKM2 in cervical cancer. Oncotarget. 2017;8:28226-28236.

This article is protected by copyright. All rights reserved. 
12. Wu H, Li Z, Wang Y, Yang P, Li Z, Li H, Wu C. MiR-106b-mediated Mfn2 suppression is critical for PKM2 induced mitochondrial fusion. Am J Cancer Res. 2016;6:2221-2234.

13. Zhang Y, Shi B, Chen J, Hu L, Zhao C. MiR-338-3p targets pyruvate kinase M2 and affects cell proliferation and metabolism of ovarian cancer. Am J Transl Res.2016;8:3266-3273.

14. Zhu H, Wu J, Zhang W, Luo H, Shen Z, Cheng H, Zhu X. PKM2 enhances chemosensitivity to cisplatin through interaction with the mTOR pathway in cervical cancer. Sci Rep. 2016;6:30788.

15. Liang J, Cao R, Zhang Y, Xia Y, Zheng Y, Li X, Wang L, Yang W, Lu Z. PKM2 dephosphorylation by Cdc25A promotes the Warburg effect and tumorigenesis. Nat Commun. 2016;7:12431.

16. Zhao Z, Song Z, Liao Z, Liu Z, Sun H, Lei B, Chen W, Dang C. PKM2 promotes stemness of breast cancer cell by through Wnt/ $\beta$-catenin pathway. Tumour Biol. 2016;37:4223-4234.

17. Israelsen WJ, Vander Heiden MG. Pyruvate kinase: Function, regulation and role in cancer. Semin Cell Dev Biol. 2015;43:43-51.

18. Yang W, Lu Z. Pyruvate kinase M2 at a glance. J Cell Sci. 2015;128:1655-1660.

19. Li Z, Yang P, Li Z. The multifaceted regulation and functions of PKM2 in tumor progression. Biochim Biophys Acta. 2014;1846:285-296.

20. Yang W, Lu Z. Regulation and function of pyruvate kinase M2 in cancer. Cancer Lett. 2013;339:153-158.

This article is protected by copyright. All rights reserved. 
21. Luo W, Semenza GL. Emerging roles of PKM2 in cell metabolism and cancer progression. Trends Endocrinol Metab. 2012;23:560-566.

22. Lakhter AJ, Hamilton J, Dagher PC, Mukkamala S, Hato T, Dong XC, Mayo LD, Harris RA, Shekhar A, Ivan M, Brustovetsky N, Naidu SR. Ferroxitosis: a cell death from modulation of oxidative phosphorylation and PKM2-dependent glycolysis in melanoma. Oncotarget. 2014;5:12694-12703.

23. Falkenius J, Lundeberg J, Johansson H, Tuominen R, Frostvik-Stolt M, Hansson J, Egyhazi Brage S. High expression of glycolytic and pigment proteins is associated with worse clinical outcome in stage III melanoma. Melanoma Res. 2013;23:452-460.

24. Fang W, Fan Y, Fa Z, Xu J, Yu H, Li P, Gu J. microRNA-625 inhibits tumorigenicity by suppressing proliferation, migration and invasion in malignant melanoma. Oncotarget. 2017;8(8):13253-13263.

25. Kang Y, Luo B, Liu J. Down-regulated microRNA-625 is a prognostic biomarker in cutaneous melanoma. Int J Clin Exp Med. 2017;10(12):16569-16574.

26. Serguienko A, Grad I, Wennerstrøm AB, Meza-Zepeda LA, Thiede B, Stratford EW, Myklebost O, Munthe E. Metabolic reprogramming of metastatic breast cancer and melanoma by let-7a microRNA. Oncotarget. 2015;6:2451-2465.

27. Chen Y, Zhang Z, Luo C, Chen Z, Zhou J. MicroRNA-18b inhibits the growth of malignant melanoma via inhibition of HIF-1 $\alpha$-mediated glycolysis. Oncol Rep. 2016;36:471-479.

This article is protected by copyright. All rights reserved. 
28. Chen Y, Cao KE, Wang S, Chen J, He B, He GU, Chen Y, Peng B, Zhou J. MicroRNA-138 suppresses proliferation, invasion and glycolysis in malignant melanoma cells by targeting HIF-1 $\alpha$. Exp Ther Med. 2016;11:2513-2518.

29. Wei S, Ma W. MiR-370 functions as oncogene in melanoma by direct targeting pyruvate dehydrogenase B. Biomed Pharmacother. 2017;90:278-286.

This article is protected by copyright. All rights reserved. 


\section{Figures}

Figure 1. PKM2 expression is up-regulated in melanoma samples. (A) PKM2 expression in melanoma tissues and normal tissues. PKM2 mRNA was examined by real time RTPCR. (B) PKM2 expression in melanoma tissues and normal tissues. PKM2 protein was examined by western blotting. (C) PKM2 expression in melanoma cells. PKM2 mRNA was examined by real time RT-PCR. (D) PKM2 expression in melanoma cells. PKM2 protein was examined by western blotting. ** $\mathrm{P}<0.01$.

A
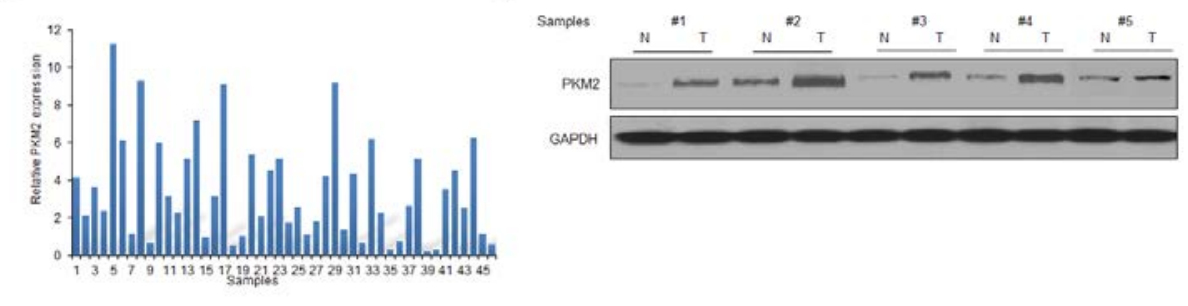

C
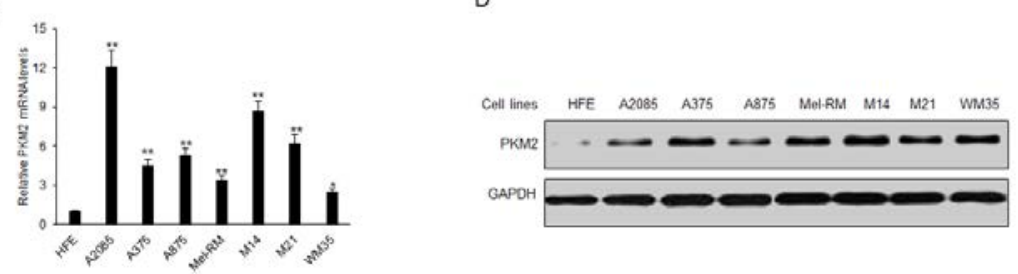

This article is protected by copyright. All rights reserved. 
Figure 2. Down-regulation of PKM2 suppresses glycolysis and reverses the drug resistance. (A-B) M14, M14R and A2085, A2085R were treated with BRAF inhibitors, and then cell proliferation was analyzed by CCR8. (C-D) Inhibition of PKM2 suppressed melanoma cell lactate production. Melanoma cells were transfected PKM2 siRNAs for 24h and lactate production was measured. (E-F) Inhibition of PKM2 suppressed melanoma cell ATP production. Melanoma cells were transfected PKM2 siRNAs for 24h and ATP production was measured. (G-H) Inhibition of PKM2 suppressed melanoma cell glucose consumption. Melanoma cells were transfected PKM2 siRNAs for 24h and glucose consumption was measured. ${ }^{*} \mathrm{P}<0.05$, ${ }^{* *} \mathrm{P}<0.01$.

A

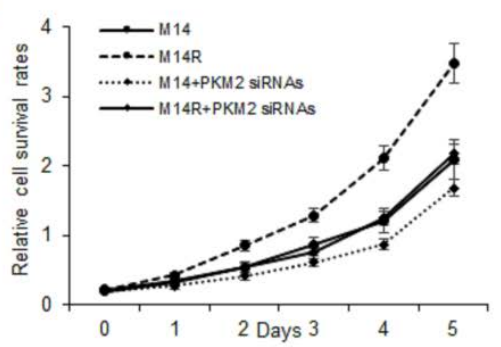

C

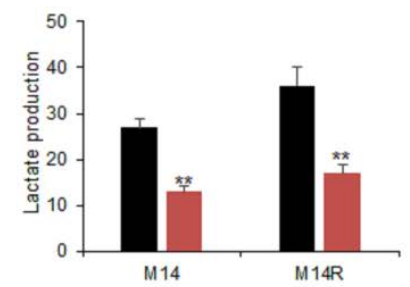

$\mathrm{E}$

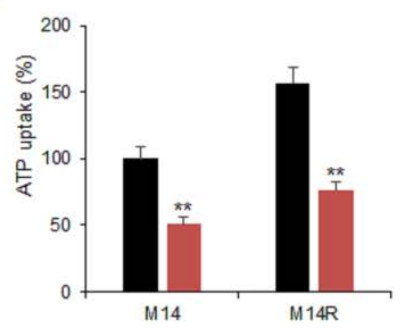

G

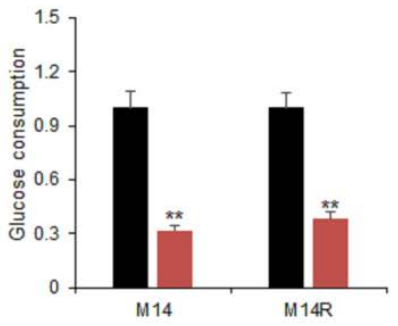

B
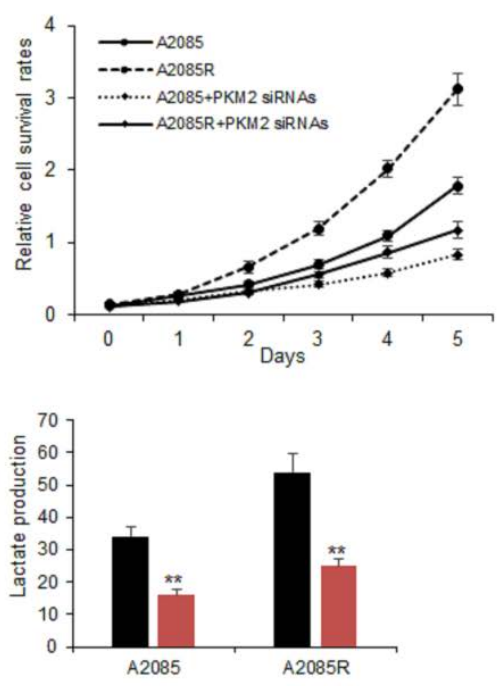

$\mathrm{F}$

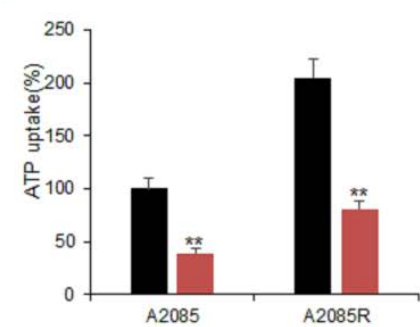

$\mathrm{H}$

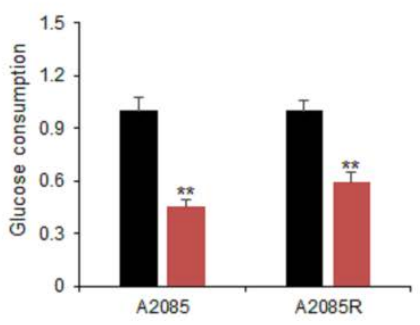

This article is protected by copyright. All rights reserved. 
Figure 3. PKM2 is a target gene of miR-625-5p in melanoma cells. (A) PKM2 is a potential target gene of miR-625-5p. The prediction result was from Targetscan. (B) Luciferase assay was used to analyze the luciferase activity of PKM2 3'UTR in M14 cells. The cells were co-transfected with miR-625-5p mimics and PKM2 3'UTR and then the dual luciferase system was used to measure the luciferase activity. (C-D) miR-625-5p down-regulated PKM2 mRNA levels in cells. The cells were transfected with miR-6255p mimics and then PKM2 mRNA was analyzed by real time RT-PCR. (E-F) miR-6255p down-regulated PKM2 protein levels in cells. The cells were transfected with miR625-5p mimics and then PKM2 was immunoblotted by western blotting. * $\mathrm{P}<0.05$, ** $\mathrm{P}<0.01$.

A

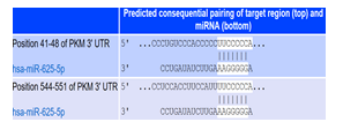

B

E

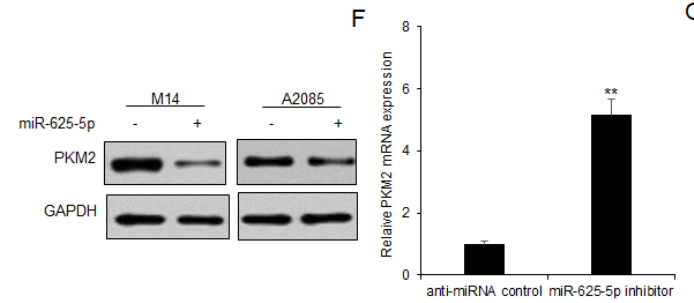

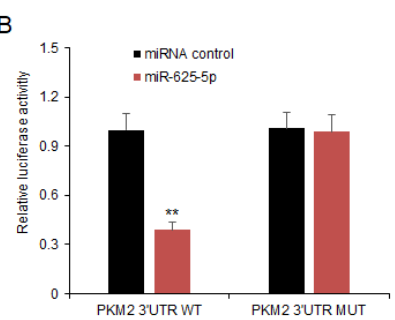
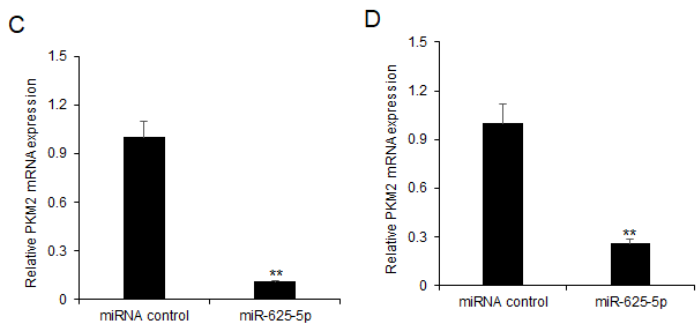

G

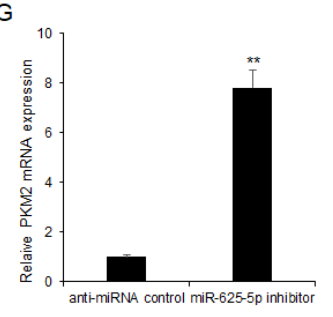

$\mathrm{H}$

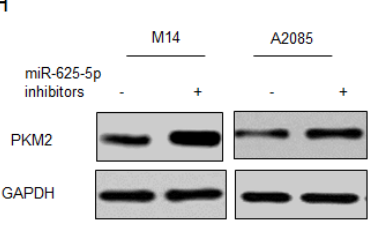

This article is protected by copyright. All rights reserved. 
Figure 4. MiR-625-5p suppresses cell proliferation and glycolysis. (A-B) M14 and A2085 were transfected with miR-625-5p for $24 \mathrm{~h}$ and then cell proliferation was analyzed by CCR8. (C-D) Cells (M14, M14R, A2085 and A2085R) were transfected with miR-625-5p or PKM2 for 24h and then lactate production was analyzed. (E-F) Cells (M14, M14R, A2085 and A2085R) were transfected with miR-625-5p or PKM2 for 24h and then ATP production was analyzed. (G-H) Cells (M14, M14R, A2085 and A2085R) were transfected with miR-625-5p or PKM2 for 24h and then glucose consumption was analyzed. * $\mathrm{P}<0.05, * * \mathrm{P}<0.01$.

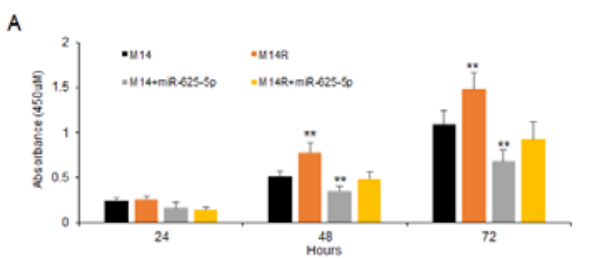

C

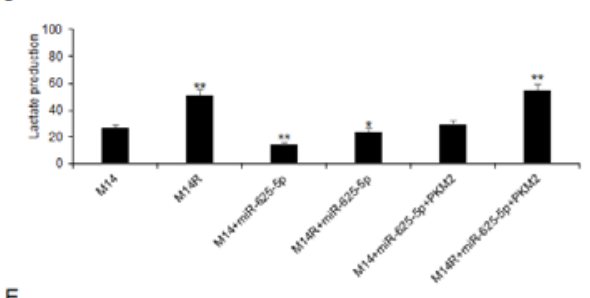

E

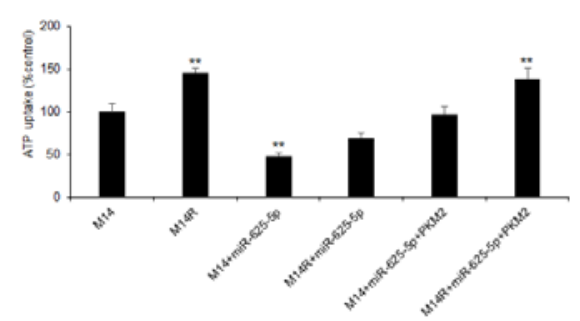

G

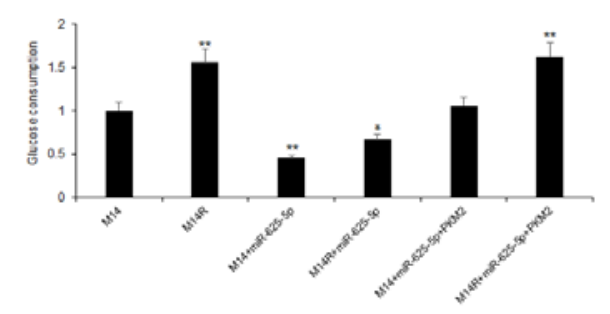

B

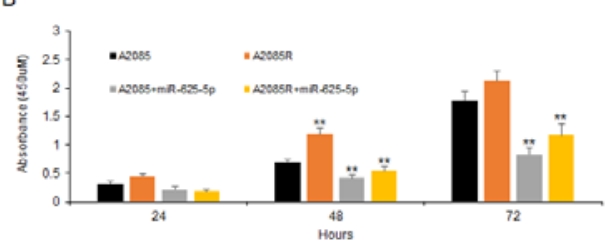

D
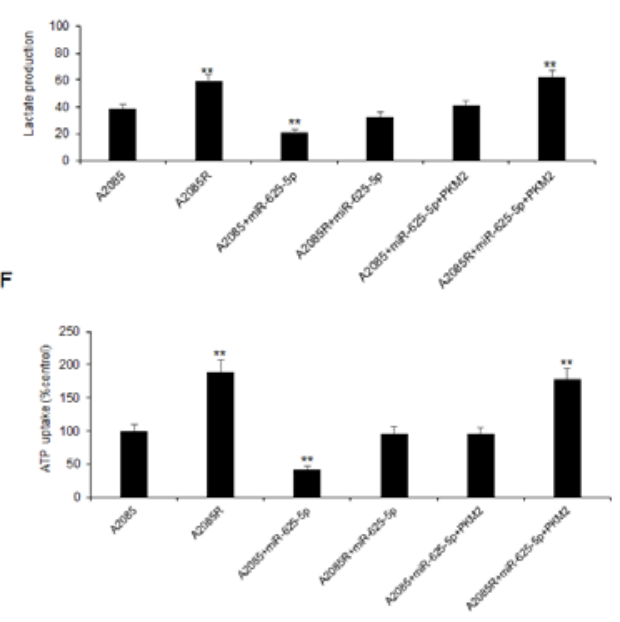

H

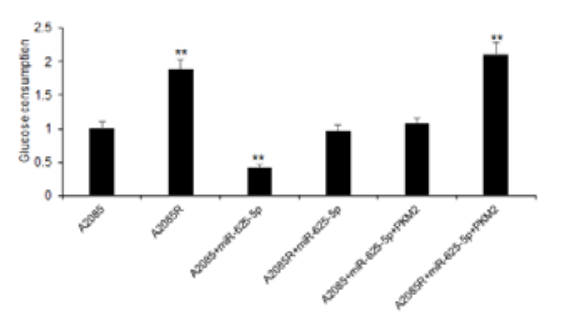

This article is protected by copyright. All rights reserved. 
Figure 5. MiR-625-5p expression is up-regulated in melanoma. (A) miR-625-5p expression in melanoma tissues and normal tissues. MiR-625-5p was examined by real time RT-PCR. (B) miR-625-5p expression in melanoma cells. MiR-625-5p was examined by real time RT-PCR. (C) MiR-625-5p was methylated in melanoma tissues. MiR-625-5p expression in melanoma cells following treatment with the demethylating agent 5-aza. (D) MiR-625-5p was methylated in melanoma cells. CpG island methylation of miR-625-5p in melanoma cell lines by BSP analysis of multiple clones in the cell lines. ${ }^{* *} \mathrm{P}<0.01$.

A

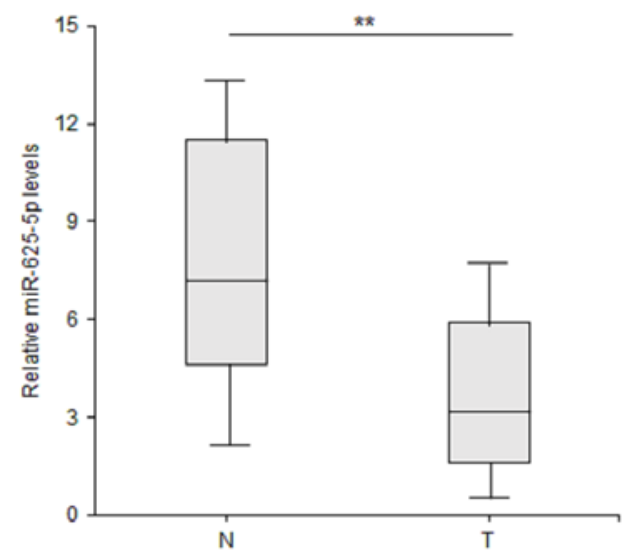

C

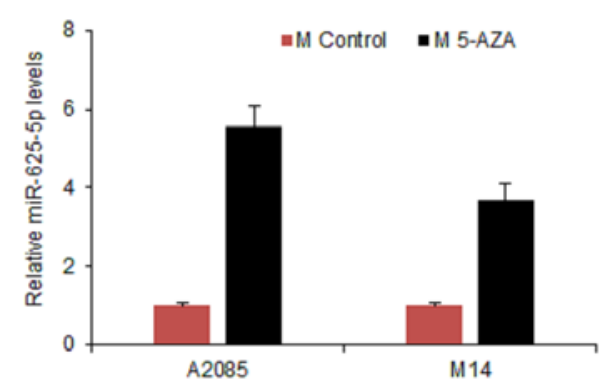

B

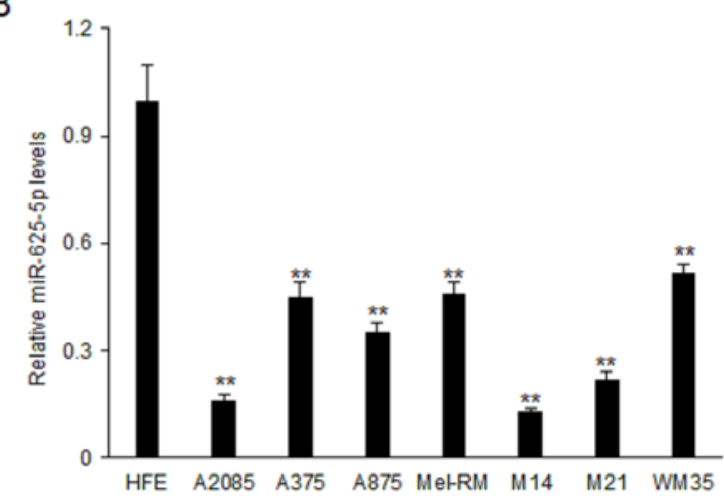

D

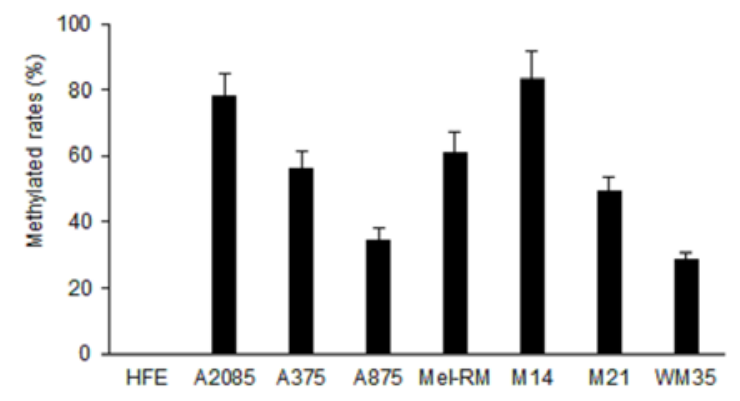

This article is protected by copyright. All rights reserved. 
Figure 6. MiR-625-5p expression is negatively related to PKM2 expression in melanoma tissues. (A) PKM2 expression was higher in melanoma tissues than the adjacent normal tissues. (B) The negative relationship between miR-625-5p and PKM2 expression in melanoma tissues. ** $\mathrm{P}<0.01$.
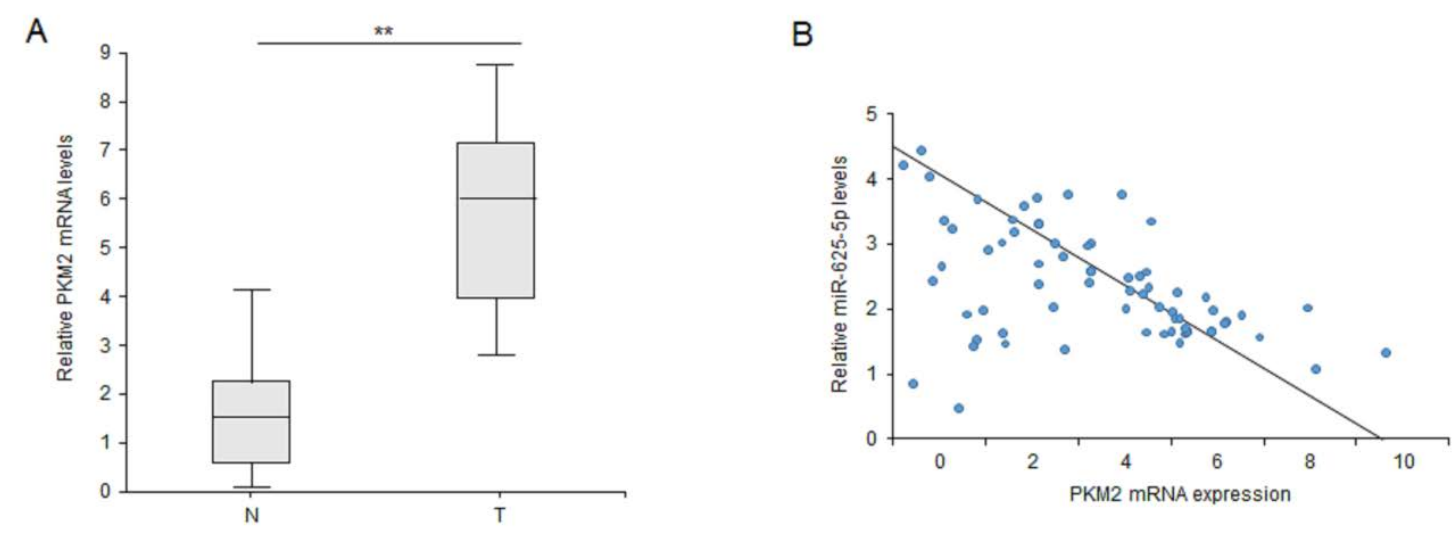

Table 1 Association between serum miR-625-5p levels and melanoma patients' clinic characteristics.

\begin{tabular}{|c|c|c|c|c|}
\hline $\begin{array}{l}\text { Clinicopathologic } \\
\text { features }\end{array}$ & n (\%) & $\begin{array}{l}\text { High miR-625-5p } \\
\text { expression }\end{array}$ & $\begin{array}{l}\text { Low miR-625-5p } \\
\text { expression }\end{array}$ & $\boldsymbol{P}$ \\
\hline Cases $(n=78)$ & & & & \\
\hline \multicolumn{5}{|l|}{ Age, years } \\
\hline$\leq 50$ & $29(37.2)$ & 10 & 19 & 0.212 \\
\hline$>50$ & $49(62.8)$ & 17 & 32 & 0.178 \\
\hline \multicolumn{5}{|l|}{ Sex } \\
\hline Male & $31(39.4)$ & 11 & 20 & 0.397 \\
\hline Female & 47 (52.6) & 16 & 31 & 0.287 \\
\hline \multicolumn{5}{|l|}{ AJCC stage } \\
\hline I- II & $35(52.1)$ & 12 & 23 & $<0.001$ \\
\hline III-IV & $43(47.9)$ & 15 & 28 & $<0.001$ \\
\hline \multicolumn{5}{|l|}{ Tumor thickness } \\
\hline$\leq 2 \mathrm{~mm}$ & $45(56.2)$ & 15 & 30 & $<0.001$ \\
\hline$>2 \mathrm{~mm}$ & $33(43.8)$ & 11 & 22 & $<0.001$ \\
\hline \multicolumn{5}{|l|}{ Ulceration } \\
\hline Present & $36(46.9)$ & 19 & 17 & 0.826 \\
\hline Absent & $42(53.1)$ & 20 & 22 & 0.786 \\
\hline \multicolumn{5}{|l|}{ Site $\mathrm{b}^{\mathrm{b}}$} \\
\hline Sun exposed & $40(50.5)$ & 18 & 22 & 0.904 \\
\hline Sun protected & $38(49.5)$ & 18 & 20 & 0.923 \\
\hline
\end{tabular}

This article is protected by copyright. All rights reserved. 
Table 2 Association between PKM2 levels and melanoma patients' clinic characteristics.

\begin{tabular}{|c|c|c|c|c|}
\hline $\begin{array}{l}\text { Clinicopathologic } \\
\text { features }\end{array}$ & n (\%) & $\begin{array}{l}\text { High PKM2 } \\
\text { expression }\end{array}$ & $\begin{array}{l}\text { Low PKM2 } \\
\text { expression }\end{array}$ & $\boldsymbol{P}$ \\
\hline \multirow{2}{*}{\multicolumn{5}{|c|}{$\begin{array}{l}\text { Cases }(n=78) \\
\text { Age, years }\end{array}$}} \\
\hline & & & & \\
\hline$\leq 50$ & $29(37.2)$ & 18 & 11 & 0.185 \\
\hline$>50$ & 49 (62.8) & 30 & 19 & 0.117 \\
\hline \multicolumn{5}{|l|}{ Sex } \\
\hline Male & 31 (39.4) & 19 & 12 & 0.459 \\
\hline Female & 47 (52.6) & 29 & 18 & 0.215 \\
\hline \multicolumn{5}{|l|}{ AJCC stage } \\
\hline I- II & 35 (52.1) & 23 & 12 & $<0.001$ \\
\hline III-IV & $43(47.9)$ & 29 & 14 & $<0.001$ \\
\hline \multicolumn{5}{|l|}{ Tumor thickness } \\
\hline$\leq 2 \mathrm{~mm}$ & $45(56.2)$ & 31 & 14 & $<0.001$ \\
\hline$>2 \mathrm{~mm}$ & $33(43.8)$ & 24 & 9 & $<0.001$ \\
\hline \multicolumn{5}{|l|}{ Ulceration } \\
\hline Present & $36(46.9)$ & 19 & 17 & 0.626 \\
\hline Absent & $42(53.1)$ & 24 & 18 & 0.693 \\
\hline \multicolumn{5}{|l|}{ Site $^{b}$} \\
\hline Sun exposed & $40(50.5)$ & 23 & 17 & 0.851 \\
\hline Sun protected & $38(49.5)$ & 22 & 16 & 0.768 \\
\hline
\end{tabular}

${ }^{\mathrm{a} S}$ Student's t test.

${ }^{\text {b}}$ Sun-exposed sites: head, neck and hands; Sun-protected sites: trunk, arm, leg, and feet.

This article is protected by copyright. All rights reserved. 


\section{University Library}

\section{- M M N E R VA A gateway to Melbourne's research publications}

Minerva Access is the Institutional Repository of The University of Melbourne

Author/s:

Zhang, H;Feng, C;Zhang, M;Zeng, A;Si, L;Yu, N;Bai, M

Title:

miR-625-5p/PKM2 negatively regulates melanoma glycolysis state

Date:

2019-03-01

Citation:

Zhang, H., Feng, C., Zhang, M., Zeng, A., Si, L., Yu, N. \& Bai, M. (2019). miR-625-5p/PKM2 negatively regulates melanoma glycolysis state. JOURNAL OF CELLULAR BIOCHEMISTRY, 120 (3), pp.2964-2972. https://doi.org/10.1002/jcb.26917.

Persistent Link:

http://hdl.handle.net/11343/285136 